\title{
RESISTÊNCIA E DESEMPENHO AGRONÔMICO DE LINHAGENS DE AMENDOIM ALTO OLEICO SEM APLICAÇÃO DE FUNGICIDAS PARA CONTROLE DE DOENÇAS FOLIARES
}

\author{
João Francisco dos Santos ${ }^{1}$, Andrea Rocha Almeida de Moraes $^{2}$, Marcos Doniseti Michelotto ${ }^{3}$, \\ Everton Luis Finoto ${ }^{3}$, Ignácio José de Godoy ${ }^{2}$
}

\footnotetext{
${ }^{1}$ Pesquisador Visitante do IAC, Campinas, SP; ${ }^{2}$ Pesquisador Científico do IAC, Campinas, SP; ${ }^{3}$ Pesquisador Científico da APTA, Polo Centro Norte, SP.
}

RESUMO: Este trabalho teve como objetivo avaliar a resistência e o desempenho agronômico de linhagens de amendoim e de cultivares divergentes quanto a resistência a doenças foliares, em ensaios de campo sem controle químico das doenças. O experimento foi conduzido no Polo Regional de Pindorama - SP, em delineamento de blocos ao acaso com três repetições dos tratamentos, constituídos por 21 linhagens e as cultivares IAC Caiapó, IAC OL 3 e IAC Top Verde. Avaliaram-se, produtividade de grãos, rendimento de descascamento, peso de 200 grãos, infestação de mancha preta no campo e ferrugem em folhas destacadas. Verificou-se que a cultivar IAC Top Verde se mostrou mais produtiva e mais resistente do que as cultivares IAC Caiapó e IAC OL 3. Nessas condições, cinco linhagens se mostraram superior a cultivar IAC Top Verde em produtividade, mas sendo semelhantes à cultivar quanto à resistência à mancha preta. No estudo de componentes principais, levando-se em consideração produtividade, rendimento de descascamento e peso de 200 grãos, as linhagens classificaram-se em três grupos, sendo o grupo A, com 13linhagens, no nível da cv IAC Top Verde, destacadamente resistente às doenças; no grupo $\mathrm{C}$, da cv IAC Caiapó, moderadamente resistente, classificaram-se 3 linhagens.

Palavras-Chave: Arachis hypogaea, mancha preta, ferrugem.

\section{INTRODUÇÃO}

As doenças foliares constituem um dos principais gargalos da cultura do amendoim, exigindo a aplicação de fungicidas ao longo de todo o ciclo de cultivo para o seu controle. Nas condições brasileiras, a principal é a mancha preta (Cercosporidium personatum), seguida pela ferrugem (Puccinia arachidis) (MORAES; GODOY, 1997)

$\mathrm{O}$ uso de fungicida propicia eficiente controle dessas doenças, mas onera significativamente $\mathrm{o}$ custo de produção. O plantio de cultivares resistente é umas das estratégias mais eficientes de controle. O melhoramento genético já vem disponibilizando cultivares moderadamente resistentes, reduzindo 


\section{Encontro Sobre a Cultura do Amendoim \\ 15 a 17 de agosto de 2019 na Estação de Eventos Cora Coralina e FCAV/UNESP, Jaboticabal-SP}

em parte a quantidade de fungicida a ser aplicada, mas novos avanços na busca por resistência são necessários.

Linhagens portadoras de alta resistência a doenças foliares, derivadas de cruzamentos entre o amendoim cultivado, Arachis hypogaea, e a espécie Arachis cardenasii, foram obtidas pelo ICRISAT (Índia), constituindo germoplasma de alto valor para o melhoramento, embora inadaptados agronomicamente para o cultivo como cultura no Brasil. Vários desses acessos foram incorporados à coleção de germoplasmas do IAC e, cruzados com linhagens e cultivares locais.

$\mathrm{O}$ acesso 69.007 foi cruzado com cultivares e linhagens do programa de melhoramento genético do IAC visando obter linhagens resistentes com caracteres agronômicos desejáveis. Posteriormente, as linhagens 321 e 333 assim obtidas, foram cruzadas com a linhagem 8008, portadora da característica "Alto Oleico", e previamente selecionada como moderadamente resistente a doenças foliares. A seleção para resistência seguiu o método genealógico e os segregantes Alto Oleicos foram selecionados na geração $\mathrm{F}_{3}$.

Assim, esse estudo, avaliou na geração $\mathrm{F}_{7}$, um grupo de linhagens selecionadas destacadas desses cruzamentos, para avaliação comparativa da resistência e de caracteres agronômicos, sem aplicação de fungicida para controle das doenças, em condições de campo sob pressão natural das doenças.

\section{MATERIAL E MÉTODOS}

Avaliou-se um grupo de 21 linhagens do programa de melhoramento do IAC (17-1, 17-3, 17 4, 17-5, 17-6, 17-7, 17-8, 17-9, 17-10, 17-11, 17-12, 17-13, 17-14, 17-15, 17-16, 17-17, 17-18, 17-19, 17-20, 17-21 e 17-22), juntamente com três controles: a cv IAC Top Verde com alta resistência à mancha preta, a cv. IAC Caiapó de resistência moderada a mancha preta e a cv IAC OL 3, produtiva, com vagem de boa qualidade e suscetível à mancha preta.

O ensaio foi conduzido em área experimental no Polo Regional de Pindorama - SP, no período das águas, na safra 2018/2019, com aplicação de inseticida conforme recomendação para a cultura (GODOY et al, 2005), mas sem controle com fungicida; com delineamento em blocos ao acaso com três repetições; em parcelas constituídas de linhas de $3 \mathrm{~m}$ de comprimento e espaçamento de 0,9 m entre linhas; na parcela de linha única, semeou-se 60 sementes por linha, uma semente a cada $5 \mathrm{~cm}$ de linha.

A avaliação da mancha preta foi realizada no campo aos 120 dias após a semeadura de acordo com escala diagramática (SUBRAHMANYAM, 1982), com notas variando de 1 a 9, conforme sintomas visuais da doença nas linhagens, sendo: 1 - ausência de manchas, e 9 - grande quantidade de manchas nas folhas remanescentes. Também nesta data, coletaram-se dez folhas de cada parcela, da parte mediana dos ramos primários para serem enviadas ao laboratório para avaliação de ferrugem, 


\section{Encontro Sobre a Cultura do Amendoim \\ 15 a 17 de agosto de 2019 na Estação de Eventos Cora Coralina e FCAV/UNESP, Jaboticabal-SP}

atribuindo-se notas de 1 a 5, levando-se em consideração o número e tamanho das lesões nos quatro folíolos de cada folha. O ensaio foi colhido aos 135 dias após a semeadura, e após a secagem das vagens, avaliou-se o peso de 200 grãos $(\mathrm{g})$ e a produção total da parcela $\left(\mathrm{kg} \mathrm{m}^{2-1}\right)$; a produtividade dos genótipos foi estimada em $\mathrm{kg} \mathrm{ha}^{-1}$.

Os dados foram submetidos as análises de variância individuais. Onde o teste $\mathrm{F}$ foi signitifcativo, os genótipos foram comparados pelo Teste de Scott-Knott a 5\% de probabilidade. Todas as variáveis foram relacionadas entre si com base no estudo de corrrelações. Por fim, as variáveis produtividade de grãos, rendimento de descascamento e peso de 200 grãos foram empregadas no estudo de componentes principais com o objetivo de agrupar as linhagens. As análises estatísticas foram realizadas no Programa Genes $(\mathrm{CRUZ}, 2013)$ e o gráfico de correlação foi elaborado no Programa R (R CORE TEAM, 2010).

\section{RESULTADOS E DISCUSSÃO}

As análises de variância são apresentadas na Tabela 1, onde verifica-se que apenas o rendimento de descascamento não apresentou $\mathrm{F}$ significativo. Os coeficientes de variação de produtividade, rendimento, peso de 200 grãos e mancha preta variaram entre 5,8 e 12,4\%, e para a ferrugem $27 \%$.

Tabela 1: Análise de variância de linhagens avaliadas em campo para resistência a mancha preta, sem controle químico da doença, em Pindorama na safra 2018/19.

\begin{tabular}{lllllll}
\hline \hline FV & GL & Produtividade & Rendimento & P200 & MP & FE \\
\hline \hline Blocos & 2 & 165163,5 & 23,4 & 9,0 & 0,08680 & 0,09722 \\
Genótipos & 23 & $2785123,7^{* *}$ & $24,6 \mathrm{~ns}$ & $323,4^{* *}$ & $3,32593^{* *}$ & $19,1588^{* *}$ \\
Resíduo & 46 & 345485,5 & 16,1 & 39,0 & 0,31506 & 0,37258 \\
\hline CV(\%) & & 12,0 & 6,0 & 5,8 & 12,4 & 27,0
\end{tabular}

P200: peso de 200 grãos (g); MP: nota para infestação de mancha preta; FE: nota para infestação da ferrugem em laboratório.

*,**: significativo a 5 e a $1 \%$ de probabilidade, respectivamente, no teste $\mathrm{F}$ da ANOVA.

Com base no teste de médias de Scott-Knott para produtividade as linhagens foram alocadas em três grupos: a, b e c (Tabela 2). O grupo a compreendeu cinco linhagens, superiores às demais e aos controles IAC Top Verde, IAC Caiapó e IAC OL3. Este grupo foi formado pelas linhagens 17-9, 17-5, 17-14, 17-19 e 17-11. O grupo b constou de 13 linhagens e da cv IAC Top Verde; o grupo c constou de três linhagens e a cv IAC Caiapó e, o grupo d, apenas da cv IAC OL 3.

Com base no teste de médias de Scott-Knott para peso de 200 grãos as linhagens foram agrupadas em três grupos. O grupo a apresentou média de $129 \mathrm{~g}$ e compreendeu as linhagens 17-8 e 17-20 e a cv IAC Caiapó. O grupo b compreendeu a linhagem 17-10 e a cv IAC OL 3, com média de 


\section{Encontro Sobre a Cultura do Amendoim \\ 15 a 17 de agosto de 2019 na Estação de Eventos Cora Coralina e FCAV/UNESP, Jaboticabal-SP}

119 g. O grupo c alocou as demais linhagens e a cv IAC Top Verde, com média de 102,9 g. Embora a maioria das linhagens possuam peso de 200 grãos semelhantes a cv IAC Top Verde, verificou-se também linhagens com peso de 200 grãos semelhantes as cultivares IAC Caiapó e IAC OL 3. Estas linhagens com grãos maiores serão o futuro das próximas gerações de amendoim para produção alternativa.

Com o objetivo de unificar as informações relativas às variáveis associadas a produção, realizou-se o estudo de componentes principais, que permitiu agrupar os genótipos com base nos dados de produtividade, rendimento e peso de 200 grãos. Com 86,2\% da variação total explicada pelos componentes, os genótipos foram divididos em três grupos, conforme apresentado na Tabela 2. $\mathrm{O}$ grupo A consistiu de 13 linhagens e a cv IAC Top Verde; o grupo B comprendeu cinco linhagens e a cv IAC OL 3; e o grupo C alocou três linhagens e a cv IAC Caiapó.

Detectaram-se diferenças significativas para a resposta dos genótipos à mancha preta (Tabela 2). Pelo teste de Scott-Knott, 20 linhagens e a cv IAC Top Verde pertencem ao grupo d que apresentaram as melhores notas para resistência à mancha preta com amplitude de variação entre 3,8 e 4,5. A cultivar IAC Top Verde, uma referência para resistência à mancha preta, foi lançada recentemente como alternativa ao mercado de amendoim orgânico. A linhagem 17-1 pertencente ao grupo c diferiu das cultivares IAC Caiapó e IAC OL 3, alocadas no grupo b e a, respectivamente.

A cv IAC Caiapó apresenta resistência moderada e a cv IAC OL 3 é suscetível, e são referências importantes no melhoramento visando resistência à mancha preta. As notas de ferrugem dos genótipos também foram agrupadas pelo teste de Scott-Knott. Os genótipos do grupo b apresentaram as melhores notas, juntamente com a cv IAC Caiapó e sete linhagens, com notas entre 1,3 e 2,3. Neste grupo, os genótipos são considerados mais resistentes do que os genótipos do grupo b, composto pela cv IAC Top Verde e 14 linhagens. A cv IAC OL 3 foi colhida antes da avaliação da ferrugem.

Tabela 2: Teste de Scott-Knott para produtividade (Prod., $\mathrm{kg} \mathrm{ha}^{-1}$ ), rendimento (Rend, \%), peso de 200 grãos (P200, g), mancha preta (MP) e ferrugem (FE) e agrupamento dos genótipos (Grupo CP).

\begin{tabular}{lllllll}
\hline \hline Genótipos & Prod $\left(\mathrm{kg} \mathrm{ha}^{-1}\right)$ & Rend $(\%)$ & P200 (g) & Grupo CP & MP & FE \\
\hline \hline $17-9$ & $6334,0 \mathrm{a}$ & 66,0 & $105,5 \mathrm{c}$ & A & $4,2 \mathrm{~d}$ & $3,3 \mathrm{a}$ \\
$17-5$ & $6031,3 \mathrm{a}$ & 67,9 & $102,1 \mathrm{c}$ & A & $4,3 \mathrm{~d}$ & $3,7 \mathrm{a}$ \\
$17-14$ & $6012,7 \mathrm{a}$ & 67,6 & $102,4 \mathrm{c}$ & A & $4,3 \mathrm{~d}$ & $3,0 \mathrm{a}$ \\
$17-19$ & $5945,0 \mathrm{a}$ & 64,9 & $99,1 \mathrm{c}$ & A & $4,2 \mathrm{~d}$ & $3,3 \mathrm{a}$ \\
$17-11$ & $5617,7 \mathrm{a}$ & 65,4 & $102,9 \mathrm{c}$ & A & $4,2 \mathrm{~d}$ & $3,0 \mathrm{a}$ \\
$17-20$ & $5358,3 \mathrm{~b}$ & 69,3 & $128,1 \mathrm{a}$ & C & $4,2 \mathrm{~d}$ & $1,3 \mathrm{~b}$ \\
$17-15$ & $5235,0 \mathrm{~b}$ & 65,8 & $104,5 \mathrm{c}$ & A & $4,3 \mathrm{~d}$ & $2,7 \mathrm{a}$ \\
$17-21$ & $5161,0 \mathrm{~b}$ & 66,5 & $100,7 \mathrm{c}$ & A & $4,2 \mathrm{~d}$ & $3,3 \mathrm{a}$ \\
$17-10$ & $5117,7 \mathrm{~b}$ & 71,8 & $118,6 \mathrm{~b}$ & C & $3,8 \mathrm{~d}$ & $1,3 \mathrm{~b}$
\end{tabular}


XVI Encontro Sobre a Cultura do Amendoim

15 a 17 de agosto de 2019 na Estação de Eventos Cora Coralina e FCAV/UNESP, Jaboticabal-SP

\begin{tabular}{lllllll}
$17-12$ & $5099,3 \mathrm{~b}$ & 68,2 & $110,3 \mathrm{c}$ & $\mathrm{A}$ & $4,0 \mathrm{~d}$ & $2,3 \mathrm{~b}$ \\
$17-13$ & $5099,0 \mathrm{~b}$ & 64,7 & $111,9 \mathrm{c}$ & $\mathrm{A}$ & $4,3 \mathrm{~d}$ & $3,0 \mathrm{a}$ \\
$17-8$ & $5093,0 \mathrm{~b}$ & 67,3 & $108,3 \mathrm{c}$ & $\mathrm{A}$ & $4,5 \mathrm{~d}$ & $2,3 \mathrm{~b}$ \\
$17-22$ & $5093,0 \mathrm{~b}$ & 66,1 & $110,1 \mathrm{c}$ & $\mathrm{A}$ & $3,8 \mathrm{~d}$ & $2,0 \mathrm{~b}$ \\
Top Verde & $5068,3 \mathrm{~b}$ & 57,8 & $97,2 \mathrm{c}$ & $\mathrm{A}$ & $3,5 \mathrm{~d}$ & $3,7 \mathrm{a}$ \\
$17-6$ & $5037,7 \mathrm{~b}$ & 66,5 & $103,0 \mathrm{c}$ & $\mathrm{A}$ & $4,5 \mathrm{~d}$ & $3,7 \mathrm{a}$ \\
$17-17$ & $4975,7 \mathrm{~b}$ & 70,3 & $97,8 \mathrm{c}$ & $\mathrm{A}$ & $4,8 \mathrm{~d}$ & $3,0 \mathrm{a}$ \\
$17-18$ & $4938,7 \mathrm{~b}$ & 72,3 & $132,4 \mathrm{a}$ & $\mathrm{C}$ & $4,2 \mathrm{~d}$ & $1,7 \mathrm{~b}$ \\
$17-16$ & $4549,7 \mathrm{~b}$ & 67,0 & $104,6 \mathrm{c}$ & $\mathrm{B}$ & $4,3 \mathrm{~d}$ & $2,7 \mathrm{a}$ \\
$17-3$ & $4537,3 \mathrm{~b}$ & 67,1 & $102,6 \mathrm{c}$ & $\mathrm{B}$ & $4,5 \mathrm{~d}$ & $3,7 \mathrm{a}$ \\
$17-4$ & $4191,3 \mathrm{c}$ & 67,5 & $97,9 \mathrm{c}$ & $\mathrm{B}$ & $3,8 \mathrm{~d}$ & $3,7 \mathrm{a}$ \\
IAC Caiapó & $3963,3 \mathrm{c}$ & 70,6 & $126,1 \mathrm{a}$ & $\mathrm{C}$ & $6,2 \mathrm{~b}$ & $2,0 \mathrm{~b}$ \\
$17-7$ & $3895,3 \mathrm{c}$ & 67,4 & $96,2 \mathrm{c}$ & $\mathrm{B}$ & $4,7 \mathrm{~d}$ & $3,3 \mathrm{a}$ \\
$17-1$ & $3136,0 \mathrm{c}$ & 67,8 & $97,3 \mathrm{c}$ & $\mathrm{B}$ & $5,2 \mathrm{c}$ & $1,3 \mathrm{~b}$ \\
IAC OL3 & $1938,3 \mathrm{~d}$ & 69,5 & $119,5 \mathrm{~b}$ & $\mathrm{~B}$ & $8,8 \mathrm{a}$ & $\mathrm{NA}$ \\
\hline \hline
\end{tabular}

Realizou-se o estudo de correlação simples entre produtividade, mancha preta, rendimento de descascamento e peso de 200 grãos (Figura 1). As correlações significativas foram coloridas e as não significativas em preto e branco; as significâncias das correlações foram testadas com o teste t a 5\% de probabilidade de erro. A estimativa de correlação entre notas de mancha preta e produtividade foi de 0,75 e significativa. A estimativa de correlação entre peso de 200 grãos e rendimento foi de 0,58 . As estimativas de correlações envolvendo notas de ferrugem e rendimento, e ferrugem e peso de 200 grãos foram significativas e negativas.

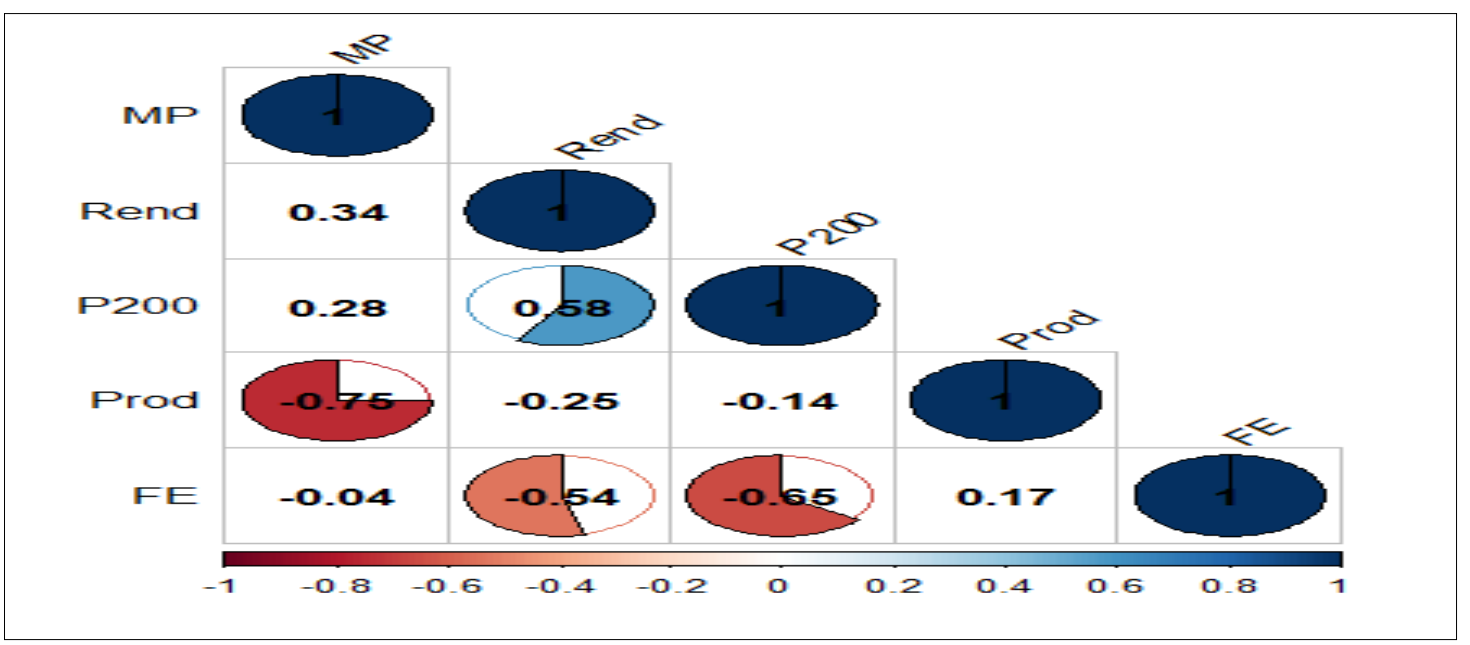

Figura 1: Estudo de correlação envolvendo MP (nota para mancha preta), rendimento de descascamento (Rend), peso de 200 grãos (P200) e ferrugem (FE), em linhagens de amendoim desenvolvidas para resistência a mancha preta. Fora da diagonal principal, as correlações coloridas são significativas a $5 \%$ pelo teste t. 


\section{Encontro Sobre a Cultura do Amendoim \\ 15 a 17 de agosto de 2019 na Estação de Eventos Cora Coralina e FCAV/UNESP, Jaboticabal-SP}

\section{CONCLUSÕES}

1. Sem controle químico das doenças foliares, a cultivar IAC Top Verde foi mais produtiva e mais resistente do que as cultivares IAC Caiapó e IAC OL 3. Nessas condições, 5 linhagens superaram a cultivar IAC Top Verde em produtividade, sendo semelhantes à cultivar quanto à resistência à mancha preta.

2. No estudo de componentes principais, levando-se em consideração produtividade, rendimento de descascamento e peso de 200 grãos, as linhagens classificaram-se em 3 grupos, sendo o grupo A, com 13linhagens, no nível da cv IAC Top Verde, destacadamente resistente às doenças; no grupo C, da cv IAC Caiapó, moderadamente resistente, classificaram-se 3 linhagens.

\section{REFERÊNCIAS BIBLIOGRÁFICAS}

CRUZ, C. D. GENES - A software package for analysis in experimental statistics and quantitative genetics. Acta Scientiarum, v.35, n.3, p.271-276, 2013.

GODOY, I. J.; MORAES, S. A.; ZANOTTO, M. D.; SANTOS, R. C. Melhoramento do Amendoim. In: A. Borém (editor). (Org.). Melhoramento de Plantas: Culturas Agronômicas. 2. ed., Viçosa, MG, 2005, 817p.

MORAES, S.A.; GODOY, I.J. Amendoim - Controle de Doenças. In: ZAMBOLIM, L. \& VALE, F.X.R. (eds.) Controle de doenças de plantas: Grandes culturas. Viçosa, Universidade Federal de Viçosa; Brasília, Ministério da Agricultura e do Abastecimento, Suprema Gráfica e Editora Ltda., 1:149, 1997. SUBRAHMANYAM, P.; McDONALD, D.; GIBBONS. R.W.; NIGAM, S.N.; NEVILL, D.J. Resistance to rust and late leafspot diseases in some genotypes of Arachis hypogaea. Peanut Science v.9, v.6-10, 1982.

R Development Core Team. 2010. R: A Language and Environment for Statistical Computing. R Foundation for Statistical Computing, Vienna, Austria. 